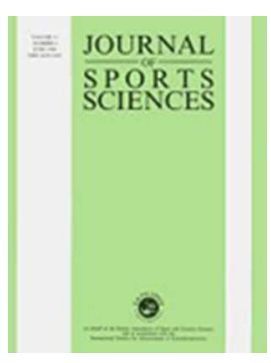

\title{
Differences in pedalling technique between road cyclists of different competitive levels
}

\begin{tabular}{|r|l|}
\hline Journal: & Journal of Sports Sciences \\
\hline Manuscript ID & RJSP-2013-0415.R4 \\
\hline Manuscript Type: & Original Manuscript \\
\hline Keywords: & cycling, biomechanics, performance, crank kinetics, joint kinematics \\
\hline & \\
\hline
\end{tabular}

SCHOLARONE ${ }^{m}$

Manuscripts 
1

2

3

4

5

6

7

8

9

10

11

12

13

14

15

16

17

18

19

20

21

22

23

24

25

26

27

28

29

30

31

32

33

34

35

36

37

38

39

40

41

42

43

44

45

46

47

48

49

50

51

52

53

54

55

56

57

58

59

60
Title

Differences in pedalling technique between road cyclists of different competitive levels 


\begin{abstract}
The purpose of this study was to compare the pedalling technique in road cyclists of different competitive levels. Eleven professional, thirteen elite and fourteen club cyclists were assessed at the beginning of their competition season. Cyclists' anthropometric characteristics and bike measurements were recorded. Three sets of pedalling $(200,250,300$ W) on a cycle ergometer that simulated their habitual cycling posture were performed at a constant cadence ( $\sim 90 \mathrm{rpm})$, while kinetic and kinematic variables were registered. The results showed no differences on the main anthropometric variables and bike measurements. Professional cyclists obtained higher positive impulse proportion $(1.5-3.3 \%$ and $\mathrm{p}<0.05)$, mainly due to a lower resistive torque during the upstroke $(15.4-28.7 \%$ and $p<0.05)$. They also showed a higher ankle range of movement (ROM, 1.1-4.0 and $\mathrm{p}<0.05)$. Significant correlations $(\mathrm{p}<0.05)$ were found between the cyclists' body mass and the kinetic variables of pedalling: positive impulse proportion $(r=-0.59--0.61)$, minimum $(r=-0.59--0.63)$ and maximum torques $(r=0.35-0.47)$. In conclusion, professional cyclists had better pedalling technique than elite and club cyclists, because they opted for enhancing pulling force at the recovery phase to sustain the same power output. This technique depended on cycling experience and level of expertise.
\end{abstract}

Keywords: cycling; biomechanics; performance; crank kinetics; joint kinematics. 


\section{Introduction}

Cycling performance depends on several physiological, training and biomechanical factors (Faria et al., 2005a; 2005b). The influence of some biomechanical factors such as aerodynamics (García-López et al., 2008), bike measurements (Peveler and Green, 2011) or noncircular chainrings (Rodríguez-Marroyo et al., 2009) on cycling performance has been demonstrated. However, the influence of other biomechanical factors such as pedalling technique (i.e. forces applied to the pedals and transferred to the cranks) is still an issue of debate (Gregor et al., 1991; Leirdal and Ettema, 2011; Theurel et al., 2012). This is in contrast to the relative consensus about the influence of the ability to save energy (i.e. pedalling efficiency) on cycling performance (Leirdal and Ettema, 2011; Hopker et al., 2012). Some recent studies have found correlations between the forces applied to the pedals and the pedalling efficiency (Zameziati et al., 2006; Candotti et al., 2007), while others have not (Korff et al., 2007; Mornieux et al., 2008). It seems that the kinetic variables selected to measure pedalling technique (i.e. pedal force effectiveness or ratio between tangential and total force applied to the pedal) could be responsible for this discrepancy (Leirdal and Ettema, 2011).

Although some educational books have affirmed that professional cyclists have better pedalling technique than recreational cyclists (Cavanagh and Sanderson, 1986; Broker, 2003), the few experimental studies on this topic are inconclusive (Sanderson, 1991; Sanderson et al, 2000). Coyle et al. (1991) observed that elite cyclists applied higher force during the downstroke than sub-elite cyclists, but sub-elite cyclists had higher pedal force effectiveness. On the contrary, other studies have shown higher pedal force effectiveness in elite cyclists than non-cyclists (Mornieux et al., 2008). Nevertheless, in both studies elite cyclists applied higher resultant force and effective impulse during the downstroke phase 
than sub-elite and non-cyclists, respectively; and this could mean a worse pedalling technique for the elite cyclists. It seems that the different absolute power outputs used by both studies to compare elite cyclist with respect to sub-elite and non-cyclists (346 vs. $311 \mathrm{~W}$ and $274 v s .232 \mathrm{~W}$, respectively) could have conditioned the interpretation of the results (Leirdal and Ettema, 2011).

Using the same absolute power outputs, Sanderson (1991) did not find significant differences in pedalling technique between competitive and non-competitive cyclists while pedalling at 100 and $235 \mathrm{~W}$. These results were justified, in part, by the relatively low power output used for the competitive cyclists. A few years later, Sanderson et al. (2000) compared recreational and competitive cyclists, who pedalled between 100 and $400 \mathrm{~W}$ (at 60, 80 and $100 \mathrm{rpm}$ ). No significant differences between the two groups were observed for forces or impulses, although recreational cyclists showed a clear trend of generating larger positive and negative impulses than competitive cyclists. These results were justified, in part, by the different anthropometric characteristics of the two groups of cyclists.

None of the previous studies evaluated pedalling kinematics as an important factor of pedalling technique (Bini et al., 2010a). Furthermore, they did not show or compare the bike measurements of the different groups of cyclists, which could affect pedalling kinematics and kinetics (Ferrer-Roca et al., 2011; Bini et al., 2014). Additionally, to the best of our knowledge, no study reported the effects of training on pedalling technique, which could be important when comparing cyclists of different competitive levels and with different training volume along the season. Therefore, the main purpose of this study was to compare the pedalling technique (kinematic and kinetic analysis) in cyclists of different competitive levels (professional, elite and club), taking into account the above-mentioned aspects. 
1

2

3

4

5

6

7

8

9

10

11

12

13

14

15

16

17

18

19

20

21

22

23

24

25

26

27

28

29

30

31

32

33

34

35

36

37

38

39

40

41

42

43

44

45

46

47

48

49

50

51

52

53

54

55

56

57

58

59

60
Secondarily, the effect of pedalling power output $(200,250$ and $300 \mathrm{~W})$ and the preseason training (professional cyclists) on the pedalling technique were analysed. 


\section{Methods}

\section{Participants}

Thirty-eight road cyclists participated in this study (Table 1) and were classified into three groups or categories according to previous conventions (Ansley and Cangley, 2009): Category 1, professional cyclists from a UCI ProTour Team $(n=11)$, which cycled more than $30.000 \mathrm{~km}$ per season, in training and competition; Category 2, elite cyclists from a UCI Continental Team $(\mathrm{n}=13)$, which cycled between 15.000 and $30.000 \mathrm{~km}$ per season; and Category 3, club cyclists belong to different competition teams $(n=14)$, which cycled between 5.000 and $15.000 \mathrm{~km}$ per season. All of them participated voluntarily and none reported any medical problem at the time of the study. They were informed of the procedures, methods, benefits, and possible risks involved in the study, and written consent was obtained before starting the study. It was approved by the University Ethics Committee and met the requirements of the Declaration of Helsinki for research on human beings.

\section{Procedures}

All cyclists were assessed at the beginning of their competition season (February-March). Additionally, nine of the professional cyclists were assessed at the beginning of their preseason (November), after a month off training. During the preseason, the professional cyclists performed a progression on the total training volume from 15 to 30 hours per week. Training contents were divided in two main blocks: endurance training and strength training. For endurance training, the cyclists performed a polarized training intensity distribution, $\sim 80, \sim 15$ and $\sim 5 \%$ of total training volume were performed at low (below the ventilatory threshold), moderate (between the ventilatory and respiratory compensation thresholds) and hard intensities (above the respiratory compensation threshold), respectively. The strength training was performed 2 days per week during 4 weeks, and consisted on 3 phases: general 
(circuit training), general explosive (squat training) and specific (starts and sprints on the bike). During this period, their maximum power output during a ramp protocol (1 min stages) increased from $5.77 \pm 0.33$ to $7.13 \pm 0.63$ watts per kilogram, and their respiratory compensation threshold increased from $4.29 \pm 0.40$ to $5.31 \pm 0.36$ watts per kilogram. The training during the preseason for the elite and club cyclists was not monitored, and their physical fitness was not evaluated.

The assessment protocol was performed in a one-day session under similar environmental conditions $\left(20-25^{\circ} \mathrm{C}, 60-65 \%\right.$ relative humidity). The cyclists arrived at the laboratory (800 m altitude) with their bikes after a 24-hour period with no hard training. Firstly, the cyclists' anthropometrical characteristics and bikes were measured. After this, the bikes' measurements (crank inclusive) and the clipless pedals were replicated in the cycle ergometer, where the cyclists performed a 10-min warm-up period at a power output of 100 $\mathrm{W}$, with a 5-min rest before starting the test. The test consisted in three sets of 5-min of pedalling at 200, 250 and $300 \mathrm{~W}$ with a 6-min rest in between. These power outputs were selected because they are representative of the effort in professional road cyclists (Vogt et al., 2007) and could be sustained by club cyclists during a short period of time (Pinot and Grappe, 2011). The cyclists received continuous feedback about their cadence and were asked to keep it constant at $90 \mathrm{rpm}$ to avoid any possible influence of cadence on the mechanical variables of pedalling (Neptune and Herzog, 1999). The selected cadence is representative of the seated pedalling cadence during flat stages (Vogt et al., 2007; Rodríguez-Marroyo et al., 2008). Simultaneous kinematic and kinetic analyses of pedalling were performed during the three sets of effort. The position during riding was standardized, with the cyclists' hands on the brakes.

\section{Anthropometric and bicycle measurements}


An anthropometric tape (Holtain LTD; Crymych, UK) and a Harpenden anthropometer (CMS instruments, London, UK) were used to measure both bike and anthropometric dimensions. All anthropometric measurements were performed by the same researcher following the international guidelines for anthropometry (Marfell-Jones et al., 2006). Inseam length of the cyclists was recorded as the distance from the ischium to the floor (Ferrer-Roca et al., 2012). Next, the main bike measurements were recorded (Figure 1). The relative saddle height (expressed in percentage) was calculated by dividing the saddle height by the inseam length (Gregor et al., 1991).

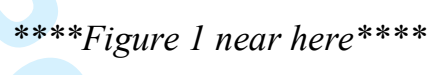

\section{Kinetic analysis}

Kinetic analysis was performed on a validated electromagnetically braked cycle ergometer (Lode Excalibur Sport, Lode BV, Groningen, Netherlands) (Reiser et al., 2000), which allowed the measurement of the torque exerted on the left and right cranks independently every $2^{\circ}$ of a complete revolution (Dorel et al., 2009; Hansen et al., 2012). Before starting the study, a dynamic calibration procedure was performed (Calibrator 2000, Lode BV, Groninger, Netherlands). Sixty essays between $25-2000 \mathrm{~W}$ of pedalling power and 40-120 rpm of pedalling cadence were compared (Calibrator 2000 vs Lode Excalibur Sport). The torque measurements showed a coefficient of variation of $0.96 \pm 1.20 \%$ ( $95 \%$ of confidence interval between $0.72-1.19 \%)$, and an intraclass correlation coefficient of $0.999(p<0.001)$. Besides, the zero adjustment was done before each testing session. All complete 5-min intervals of the three sets of pedalling were recorded (LEM software, Lode BV, Groninger, Netherlands). For the kinetic analysis, the mean of $\sim 360$ complete revolutions from minute one to minute five were selected, and values of right and left cranks were averaged (Figure 2). The following mechanical variables were directly obtained from the software: pedalling 
rate, maximum torque and minimum torque. Additionally, torque-time data and crank arm length were exported to ASCI format to calculate the rest of the mechanical variables: positive impulse, negative impulse and the relationship between both variables. This relationship is represented as the positive impulse proportion (expressed in percentage).

$$
\text { Positive impulse proportion }(\%)=\frac{\text { positive impulse } \times 100}{\text { positive impulse }+ \text { |negative impulse } \mid}
$$

****Figure 2 near here ${ }^{* * * *}$

\section{Kinematic analysis}

Kinematic analysis of the cyclists' right side was performed assuming symmetry of motion between left and right sides (Heil et al., 1997). Five reflective markers of $10 \mathrm{~mm}$ diameter were attached to the skin of the cyclists (greater trochanter, lateral femoral epicondyle and lateral malleolus) and to the bikes (crank and pedal axes of rotation) (Bini et al., 2010a; Ferrer-Roca et al., 2012). A high-speed digital video camera (Sony Handycam HDR-HC7, Sony Inc, Europe, $200 \mathrm{~Hz}$ and $720 \times 576$ pixels) and a floodlight were positioned $4 \mathrm{~m}$ away from the sagittal plane, where a calibration frame was placed $(1.00 \times 1.20 \mathrm{~m})$. Automatic tracking, processing and analysing data were performed by a specific software (KinescanIBV, Version 2001, Institute of Biomechanics of Valencia, Valencia, Spain) (García-López et al., 2008). Six complete revolutions were analysed in minutes 2 and 4 of every trial as representative values. Sagittal hip, knee and ankle angles (Figure 2) were determined following previous conventions (Bini and Diefenthaeler, 2010). Angular position values were expressed as flexion (minimum angle) and extension (maximum angle). The range of movement (ROM) was also determined.

\section{Statistical analysis}


The results are expressed as mean \pm SD. SPSS + V.17.0 statistical software was used (SPSS, Inc., Chicago, IL, USA). Shapiro-Wilk test was applied to ensure a Gaussian distribution of all variables. Pearson correlation coefficient (r) was used to assess the relationships between variables. The calibration errors and the reliability of the Lode Excalibur Sport ergometer for torque measurements were assessed using the coefficient of variation and the intraclass correlation coefficient (García-López et al., 2013). Multivariable Analysis of Variance (MANOVA) was used to analyse the effect of competitive level (professional, elite and club) and pedalling power output (200, 250 and $300 \mathrm{~W})$ on pedalling technique (kinematics and kinetics), taking into account as covariates the bike and anthropometric dimensions, as well as kilometres of training. One-way Analysis of Variance (ANOVA) was used to analyse the effect of competitive level (professional, elite and club) on cyclists' characteristics and bicycle measurements. ANOVA with repeated measures was used to analyse the effect of the preseason training (professional cyclists) on pedalling technique, taking into account the body mass changes during the preseason as a covariate. Newman-Keuls post hoc analysis was used to establish statistical differences between means. Effect sizes (ES) of the differences (Cohen's $d$ ) were also calculated (Cohen, 1988). The magnitude of the differences were considered to be trivial $(\mathrm{ES}<0.2)$, small $(0.2 \leq \mathrm{ES}<0.5)$, moderate $(0.5 \leq$ $\mathrm{ES}<0.8)$, and large $(\mathrm{ES} \geq 0.8)$. Values of $\mathrm{p}<0.05$ were considered statistically significant. 


\section{Results}

Table 1 shows significant effects of competitive level on age ( $d=0.83$, large effect), cycling experience $(d=0.89$, large effect), training volume $(d=0.65$, moderate effect), body mass index $(d=0.94$, large effect) and distance between the front of the saddle and the middle of the handlebars $(d=0.86$, large effect).

\section{****Table 1 near here ${ }^{* * * *}$}

Table 2 shows significant effects of competitive level on maximum torque $(d=0.56$, moderate effect), minimum torque $(d=1.33$, large effect) and positive impulse proportion $(d$ $=0.67$, moderate effect). Professional cyclists obtained higher positive impulse proportion (between 1.5-2.7\% and 1.7-3.3\%), and lower maximum (between 2.6-7.0\% and 4.9-7.0\%) and minimum torques (between 15.4-20.4\% and 20.0-28.7\%) compared to the elite and club cyclists, respectively. Significant effects of pedalling power output on maximum torque $(d=$ 7.90, large effect), minimum torque $(d=7.40$, large effect) and positive impulse proportion $(d=7.74$, large effect) were also observed. No significant combined effect of competitive level and pedalling power output on kinetic variables of pedalling was found. However, significant correlations $(\mathrm{p}<0.05)$ were found between cyclists' body mass and kinetic variables at 200, 250 and $300 \mathrm{~W}$. Heavier cyclists obtained a lower positive impulse proportion $(\mathrm{r}=-0.59,-0.59$ and -0.61 , respectively), and minimum torque $(\mathrm{r}=-0.63,-0.60$ and -0.59 , respectively) and maximum torque were higher ( $r=0.35,0.42$ and 0.47 , respectively) to pedalling at the same power output when compared to slim cyclists.

****Table 2 near here $* * * *$ 
Table 3 shows significant effects of competitive level on ankle ROM ( $d=1.04$, large effect) and hip flexion $(d=0.46$, small effect). Additionally, pedalling power increased ankle flexion $(115.2 \pm 7.3,114.0 \pm 6.6$ and $112.9 \pm 6.7$ degrees, respectively; $d=0.55$, moderate effect $)$ and ankle $\operatorname{ROM}(21.4 \pm 6.4,22.1 \pm 6.0$ and $23.5 \pm 5.5$ degrees; $d=0.36$, small effect). No significant combined effect of competitive level and pedalling power output on kinematic variables was found.

\section{****Table 3 near here ${ }^{* * * *}$}

Table 4 shows a significant decrease in the minimum torque $(\mathrm{d}=0.95$, large effect $)$ after the preseason training in the professional cyclists group, without changes in the rest of biomechanical variables. However, taking into account the body mass before and after training as covariate $(70.0 \pm 6.7 v s 68.1 \pm 5.1 \mathrm{~kg}, d=2.55$, large effect), no significant effect of the preseason on kinetic and kinematic variables was observed.

****Table 4 near here ${ }^{* * * *}$ 


\section{Discussion}

The main outcome of the present study was to demonstrate that competitive level affects pedalling technique in road cyclists (Table 1). Professional cyclists had a better pedalling technique (i.e. higher positive impulse proportion) than elite and club cyclists when pedalling at $200 \mathrm{~W}$ or more. This was due to the lower minimum torque during the upstroke (less negative torque values), and to kinematic differences in ankle (increased range of movement). These findings are particularly significant because previous studies have not shown differences in pedalling technique (kinetic analysis) between cyclists of different competitive levels (Coyle et al., 1991; Sanderson, 1991; Sanderson et al., 2000). Additionally, pedalling kinematics was evaluated as an important factor of pedalling technique (Bini et al., 2010a).

To date, there is controversy about the use of pulling technique (less negative torque values during upstroke) in road cycling. Two previous studies analysed the acute effects of changing pedalling technique on physiological (i.e. gross efficiency) and biomechanical variables (i.e. pedal force effectiveness). Briefly, the cyclists were encouraged to active pulling-up action during the upstroke, and biomechanical variables improved (e.g. index of pedal force effectiveness increased between 14.2-23.5\%) while physiological variables declined (e.g. gross efficiency decreased between 0.8-1.2\%) (Korff et al., 2007; Mornieux et al., 2008). They used sets of submaximal pedalling from 3.30 to $6.00 \mathrm{~min}$. Contrary, a recent study demonstrated that the pulling technique did not affect gross efficiency after $15 \mathrm{~min}$ of submaximal pedalling, while negative force during upstroke decreased $\sim 18 \%$ (Theurel et al., 2012). In addition, it could reduce muscle fatigue after prolonged cycling exercise by decreasing the activity of the main leg extensor muscles during downstroke (i.e. vastus lateralis and rectus femoris as knee extensor) and increasing the activity of the main leg 
flexor muscles during upstroke (i.e. rectus femoris as hip flexor, biceps femoris and tibialis anterior) (Mornieux et al., 2008; Theurel et al., 2012).

In the same line of evidence, another recent study obtained an increase in the performance and a reduction of the phase where the negative torque occurs after heavy strength training (Hansen et al., 2012). They hypothesized that a higher hip-flexor muscles strength could have been responsible for these changes, allowing a better lift of the leg mass against gravity, improving the transition around the top dead centre and delaying the fatigue. These two last studies are in consonance with the results of the present study, where the professional cyclists showed less negative torque values during the upstroke than elite and club cyclists (between 15.4 and 28.7\%), which could be an adaptation to training. Hip-flexor muscles strength and timing of muscle activity could be better in the professional cyclists, but future studies measuring strength and using electromyography are necessary to confirm this hypothesis. The present study did not change the natural technique of the cyclists, which is an important difference with respect to some of the above-mentioned studies (Korff et al., 2007; Mornieux et al., 2008).

The bike measurements of the different groups of cyclists were registered and compared (Table 1). For example, relative saddle height (percentage of inseam length) of all groups of cyclists was between $109.2-109.5 \%$, into the range of $108.6-110.4 \%$, which was recently recommended (Ferrer-Roca et al., 2012). This is important, because previous studies did not take this aspect into account (Coyle et al., 1991; Sanderson, 1991; Sanderson et al., 2000), and it could have affected the pedalling technique (Bini et al., 2010b; Ferrer-Roca et al., 2012). Besides, in the present study, a multivariable analysis of variance taking into account the bicycle dimensions as covariate was performed. Therefore, the differences in pedalling technique were not due to different bicycle configurations, because only the distance 
between the front of the saddle and the middle of the handlebars was lower in the club cyclists, possibly due to their less cycling experience, which could imply a more comfortable fit. This difference did not affect the interpretation of the results, because this distance was similar between professional and elite cyclists, while their pedalling technique was different.

Differences in pedalling technique were due to cycling experience (Table 1), which is one of the main factors in achieving a high level of sporting performance (Tucker and Collins, 2012), and specifically a high level of cycling performance (Edwards et al., 2009). Differences were not due to age (similar between professional and club cyclists), body mass index (similar between professional and elite cyclists), cyclists' body mass or height (similar between the three groups) or training volume at the beginning of the competition season (highest in the professional cyclists). The differences in training volume $(3000-4000 \mathrm{~km})$ could not fully justify the differences in pedalling technique, because the effects of cycling $\sim 9000 \mathrm{~km}$ in the professional cyclists represented changes in kinetic variables lower than half of the differences between groups (Tables 2 and 4). Additionally, when cyclists' body mass at the beginning and at the end of the preseason was taken into account as covariate, no significant overall effect of this training on both kinematic and kinetics variables was observed. Thus, the decrease in minimum torque could have been due to the loss of body mass and not to the preseason training.

The correlation between the cyclists' body mass and the kinetic variables highlights the importance of taking into account the body mass when different groups of cyclists are compared (assuming that heavier cyclists had greater leg mass). During pedalling at $90 \mathrm{rpm}$ the inertial effect of the legs represented $\sim 40 \%$ of the total crank torque (Neptune and Herzog, 1999), and this could mean an increase in the minimum torque during upstroke (Sanderson, 1991). Previous studies which compared pedalling technique in road cyclists 
used groups of cyclists with differences in body mass between 5-7 kg (Sanderson, 1991; Sanderson et al., 2000), and their statistical models did not had into account the body mass as covariate. The non-controlled mass effect on pedalling technique could explain why these studies did not find differences between cyclists of different competitive levels.

The increase in power output affected kinetic variables (Table 2), and the maximum torque during downstroke increased while the torque values during upstroke were less negative, causing better positive impulse proportion as power output increased. These results were in line with previous studies where the main effect of increasing power output at constant cadence was an increase in the maximum force applied to the pedal (Sanderson, 1991; Sanderson et al., 2000). The decrease in minimum torque as power output increased was considered a "strategy of the rider to improve the effective application of force by reducing the need for the propulsive leg to overcome the recovery leg" (Sanderson, 1991). Kinetic differences between groups were higher at 250 and $300 \mathrm{~W}$ than at $200 \mathrm{~W}$, possibly because it was a relatively low power output for the competitive cyclists to highlight their superior pedalling technique (Sanderson et al., 2000). The present study utilized no more than $300 \mathrm{~W}$ of power output because club cyclists were not able to sustain it for $5 \mathrm{~min}$.

The fact that power output affected kinematic variables was in line with a previous study, which demonstrated changes in the ankle joint (higher flexion and ROM), but not at the knee joint (Bini and Diefenthaeler, 2010). These results were very similar to those obtained in the present study when different competitive levels (Table 3$)$ and power outputs (200, 250 and $300 \mathrm{~W})$ were compared, and could be an adaptation of the professional cyclists to pedal normally at highest power outputs. Other studies agreed with these results, showing that ankle joint was more sensitive than the knee joint to changes in pedalling biomechanics (Savelberg et al., 2003; Shan, 2008). The results of the present study showed differences in 
ankle ROM between the three groups of cyclists (Table 3), and were in accordance with previous observations (Cavanagh and Sanderson, 1986; Chapman et al. 2009). Chapman et al. (2009) also observed that ankle ROM was higher (i.e. $21.5 \pm 9.0^{\circ}$ vs $13.2 \pm 7.7^{\circ}$, respectively) and inter-joint coordination was better (i.e. hip vs ankle flexion-extension and knee $v s$ ankle flexion-extension) in elite cyclists when compared to novice cyclists.

During the preseason, the maximum torque and the positive impulse proportion of the professional cyclists did not change (Table 4). The minimum torque decreased, possibly due to the loss of body mass $(\sim 2 \mathrm{~kg})$. The major differences were observed at $300 \mathrm{~W}$, possibly because the cyclists highlighted their best potential (Sanderson et al., 2000). The nonsignificant changes in positive impulse proportion at 200, 250 and $300 \mathrm{~W}(0.3,1.0$ and $1.4 \%$, respectively) were well below the observed differences between professional and club cyclists $(1.7,2.2$ and $3.3 \%$, respectively) (Table 2). To the best of our knowledge, no previous longitudinal studies have investigated the effects of training on the mechanical parameters of pedalling, so it was difficult to compare these results. Monitoring the effect of training on physiological variables such as gross mechanical efficiency is more habitual in the scientific literature (Hopker et al., 2012), but unfortunately, physiological variables were not recorded in this study. Therefore, future studies should solve the main limitations of this study, which were the non-monitored preseason training and physical fitness of the elite and club cyclists, and the non-simultaneous recording of biomechanical and physiological variables (Korff et al., 2007; Edwards et al., 2009; Leirdal and Ettema, 2011; Hopker et al., 2012). Besides, another possible limitation could be to use the greater trochanter measurement instead of the anterior-superior iliac spine to estimate the hip joint centre, although this have little influence on joint angular kinematics (Neptune and Hull, 1995).

\section{Conclusions}


Professional cyclists had better pedalling technique than elite and club cyclists, because they needed a lower positive impulse proportion (between 1.5-3.3\%) to pedalling at the same power output. This was due to a lower minimum torque during the upstroke (less negative torque values between 15.4 and $28.7 \%$ ) and to a higher ROM in the ankle joint. The differences in pedalling technique depended on cycling experience (i.e. more years of practice) and level of expertise, and did not depend on other variables such as bike measurements, anthropometry or training volume.

\section{Acknowledgments}

The authors thank the cyclists who participated in this study and the Euskaltel-Euskadi Cycling Team for its collaboration during the study, and for its authorization to communicate the results. This work has been supported by the Spanish Council of Sports (CSD) (12/UPB10/07), Spain. Thanks also to the Basque Government for supporting this research project with a predoctoral grant (2011-14). The authors have no conflicts of interest to disclose. 


\section{References}

Ansley, L., Cangley, P. (2009). Determinants of "optimal" cadence during cycling. European Journal of Sport Science, 9, 61-85.

Bini, R.R., Diefenthaeler, F. (2010). Kinetics and kinematics analysis of incremental cycling to exhaustion. Sports Biomechanics, 9, 223-235.

Bini, R.R., Diefenthaeler, F., Mota, C.B. (2010a). Fatigue effects on the coordinative pattern during cycling: kinetics and kinematics evaluation. Journal of Electromyography and Kinesiology, 20, 102-107.

Bini, R.R., Tamborindeguy, A.C., Mota, C.B. (2010b). Effects of saddle height, pedaling cadence, and workload on joint kinetics and kinematics during cycling. Journal of Sport Rehabilitation, 19, 301-314.

Bini, R.R., Hume, P.A., Kildinga, A.E. (2014). Saddle height effects on pedal forces, joint mechanical work and kinematics of cyclists and triathletes. European Journal of Sport Science, $14,44-52$.

Broker, J.F. (2003). Cycling biomechanics: road and mountain. In E.R. Burke (Ed.), High Tech Cycling (pp. 119-146). Champaign, Illinois: Human Kinetics.

Candotti, C.T., Ribeiro, J., Soares, D.P., De Oliveira, A.R., Loss, J.F., Guimarães, A.C. (2007). Effective force and economy of triathletes and cyclists. Sports Biomechanics, 6, 3143.

Cavanagh, P.R., Sanderson, D.J. (1986). The Biomechanics of cycling: studies of the pedalling mechanics of elite pursuit riders. In E.R. Burke (Ed.), Science of Cycling (pp. 91122). Champaign, Illinois: Human Kinetics.

Chapman, A., Vicenzino, B., Blanch, P., Hodges, P. (2009). Do differences in muscle recruitment between novice and elite cyclists reflect different movement patterns or less skilled muscle recruitment? Journal of Science and Medicine in Sport, 12, 31-34. 
Cohen, J (1988). Statistical power analysis for the behavioral sciences ( $2^{\text {nd }}$ Edition). Hillsdale, New Jersey: Lawrence Erlbaum Associates.

Coyle, E.F., Feltner, M.E., Kautz, S.A., Hamilton, M.T., Montain, S.J., Baylor, A.M., Abraham, L.D., Petrek, G.W. (1991). Physiological and biomechanical factors associated with elite endurance cycling performance. Medicine and Science in Sports and Exercise, 23, 93-107.

Dorel, S., Couturier, A., Hug, F. (2009). Influence of different racing positions on mechanical and electromyographic patterns during pedalling. Scandinavian Journal of Medicine and Science in Sports, 19, 44-54.

Edwards, L.M., Jobson, S.A., George, S.R., Day, S.H., Nevill, A.M. (2005). Whole-body efficiency is negatively correlated with minimum torque per duty cycle in trained cyclists. Journal of Sports Sciences, 27, 319-325.

Faria, E.K., Parker, D.L., Faria, I.E. (2005a). The science of cycling. Factors affecting performance - Part 2. Sports Medicine, 35, 313-337.

Faria, E.K., Parker, D.L., Faria, I.E. (2005b). The science of cycling. Physiology and Training - Part 1. Sports Medicine, 35, 285-312.

Ferrer-Roca, V., Roig, A., Galilea, P., García-López, J. (2012). Influence of saddle height on lower limb kinematics in well-trained cyclists. Static versus dynamic evaluation in bike fitting. Journal of Strength and Conditioning Research, 26, 3025-3029.

García-López, J., Rodríguez-Marroyo, J.A., Juneau, C.E., Peleteiro, J., Martínez, A.C., Villa, J.G. (2008). Reference values and improvement of aerodynamic drag in professional cyclists. Journal of Sports Sciences, 26, 277-286.

García-López, J., Morante, J.C., Ogueta-Alday, A., Rodríguez-Marroyo, J.A. (2013). The type of mat (Contact vs. Photocell) affects vertical jump height estimated from flight time. Journal of Strength and Conditioning Research, 27, 1162-1167. 
Gregor, R.J., Broker, J.P., Ryan, M.M. (1991). The biomechanics of cycling. Exercise and Sports Sciences Reviews, 19, 127-169.

Hansen, E.A., Rønnestad, B.R., Vegge, G., Raastad, T. (2012). Cyclists' improvement of pedaling efficacy and performance after heavy strength training. International Journal of Sports Physiology and Performance, 7, 313-321.

Heil, D.P., Derrick, T.R., Whittlesey, S. (1997). The relationship between preferred and optimal positioning during submaximal cycle ergometry. European Journal of Applied Physiology, 75, 160-165.

Hopker, J., Coleman, D., Jobson, S.A., Passfield, L. (2012). Inverse relationship between VO2max and gross efficiency. International Journal of Sports Medicine, 33, 789-794.

Korff, T., Romer, L.M., Mayhew, I., Martin JC. (2007). Effect of pedaling technique on mechanical effectiveness and efficiency in cyclists. Medicine and Science in Sports and Exercise, 39, 991-995.

Leirdal, S., Ettema, G. (2011). Pedaling technique and energy cost in cycling. Medicine and Science in Sports and Exercise, 43, 701-705.

Marfell-Jones, M., Olds, T., Stewart, A., Carter, J.E.L. (2006). International standards for anthropometric assessment. Potchefstroom, South Africa: ISAK.

Mornieux, G., Stapelfeldt, B., Gollhofer, A., Belli, A. (2008). Effects of pedal type and pullup action during cycling. International Journal of Sports Medicine, 29, 817-822.

Neptune, R.R., Herzog, W. (1999). The association between negative muscle work and pedaling rate. Journal of Biomechanics, 32, 1021-1026.

Peveler, W.W., Green, J.M. (2011). Effects of saddle height on economy and anaerobic power in well-trained cyclists. Journal of Strength and Conditioning Research, 25, 629-633. Pinot J, Grappe F. (2011). The record power profile to assess performance in elite cyclists. International Journal of Sports Medicine, 32, 839-844. 
Reiser, M., Meyer, T., Kindermann, W., Daugs, R. (2000). Transferability of workload measurements between three different types of ergometer. European Journal of Applied Physiology, 82, 245-249.

Rodríguez-Marroyo, J.A., García-López, J., Chamari, K., Córdova, A., Hue, O., Villa, J.G. (2009). The rotor pedaling system improves anaerobic but not aerobic cycling performance in professional cyclists. European Journal of Applied Physiology, 106, 87-94.

Rodríguez-Marroyo, J.A., García-Lopez, J., Villa, J.G., Cordova, A. (2008). Adaptation of pedaling rate of professional cyclist in mountain passes. European Journal of Applied Physiology, 103, 515-22.

Sanderson, D.J., Henning, E.M., Black, A.H. (2000). The influence of cadence and power output on force application and in shoe pressure distribution during cycling by competitive and recreational cyclists. Journal of Sports Sciences, 18, 173-181.

Sanderson, D.J. (1991). The influence of cadence and power output on the biomechanics of force application during steady-rate cycling in competitive and recreational cyclists. Journal of Sports Sciences, 9, 191-203.

Savelberg, H., Van de Port, I., Willems, P. (2003). Body configuration in cycling affects muscle recruitment and movement pattern. Journal of Applied Biomechanics, 19, 310-324.

Shan, G. (2008). Biomechanical evaluation of bike power saver. Applied Ergonomics, 39, $37-45$.

Theurel, J., Crepin, M., Foissac, M., Temprado, J.J. (2012). Effects of different pedalling techniques on muscle fatigue and mechanical efficiency during prolonged cycling. Scandinavian Journal of Medicine and Science in Sports, 22, 714-721.

Tucker, R., Collins, M. (2012). What makes champions? A review of the relative contribution of genes and training to sporting success. British Journal of Sports Medicine, 46, 555-561. 
1

2

3

4

5

6

7

8

9

10

11

12

13

14

15

16

17

18

19

20

21

22

23

24

25

26

27

28

29

30

31

32

33

34

35

36

37

38

39

40

41

42

43

44

45

46

47

48

49

50

51

52

53

54

55

56

57

58

59

60
Vogt, S., Schumacher, Y.O., Roecker, K., Dickhuth, H.H., Schoberer, U., Schmid, A., Heinrich, L. (2007). Power Output during the Tour de France. International Journal of Sports Medicine, 28, 756-761.

Zameziati, K., Mornieux, G., Rouffet, D., Belli, A. (2006). Relationship between the increase of effectiveness indexes and the increase of muscular efficiency with cycling power.

European Journal of Applied Physiology, 96, 274-281. 
Table 1. Characteristics (Mean $\pm \mathrm{SD}$ ) of the three groups of cyclists (Professionals, Elite and Club) and their bicycles.

\begin{tabular}{|c|c|c|c|c|c|}
\hline & & $\begin{array}{l}\text { Professional } \\
\quad(\mathrm{n}=11)\end{array}$ & $\begin{array}{c}\text { Elite } \\
(\mathrm{n}=13)\end{array}$ & $\begin{array}{c}\text { Club } \\
(n=14)\end{array}$ & $\begin{array}{c}\text { All cyclists } \\
(\mathrm{n}=38)\end{array}$ \\
\hline \multirow{6}{*}{ 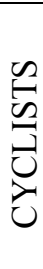 } & Age (yr) & $26.7 \pm 2.6^{*}$ & $21.6 \pm 1.3 t$ & $27.9 \pm 7.0$ & $25.4 \pm 5.2$ \\
\hline & Cycling experience (yr) & $14.9 \pm 2.3 * \dagger$ & $9.8 \pm 1.4$ & $8.3 \pm 6.8$ & $10.8 \pm 5.1$ \\
\hline & Training volume (km) & $9091 \pm 1841 * \dagger$ & $6719 \pm 1327$ & $6208 \pm 1547$ & $7245 \pm 2693$ \\
\hline & Height (m) & $178.2 \pm 6.4$ & $180.2 \pm 3.9$ & $177.5 \pm 5.7$ & $178.6 \pm 5.4$ \\
\hline & Weight (kg) & $67.7 \pm 5.0$ & $68.0 \pm 5.0$ & $70.1 \pm 5.6$ & $68.7 \pm 5.2$ \\
\hline & $\mathrm{BMI}\left(\mathrm{kg} \cdot \mathrm{m}^{-2}\right)$ & $21.3 \pm 1.0$ & $20.9 \pm 1.1 \ddagger$ & $22.3 \pm 1.6$ & $21.5 \pm 1.4$ \\
\hline \multirow{6}{*}{ 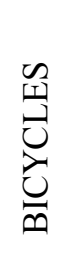 } & Saddle height $(\mathrm{cm})$ & $76.2 \pm 4.7$ & $77.0 \pm 2.7$ & $75.0 \pm 3.7$ & $76.0 \pm 3.7$ \\
\hline & Saddle height (\%IL) & $109.5 \pm 2.5$ & $109.4 \pm 2.6$ & $109.2 \pm 2.3$ & $109.3 \pm 2.4$ \\
\hline & Saddle back $(\mathrm{cm})$ & $7.3 \pm 2.0$ & $8.2 \pm 1.3$ & $6.8 \pm 1.3$ & $7.4 \pm 1.6$ \\
\hline & Crank arm length (mm) & $173.6 \pm 1.3$ & $174.6 \pm 0.9$ & $173.1 \pm 1.5$ & $173.8 \pm 1.4$ \\
\hline & Handlebar-D $(\mathrm{cm})$ & $56.7 \pm 4.3 \dagger$ & $56.8 \pm 2.1 \ddagger$ & $54.1 \pm 2.7$ & $55.8 \pm 3.3$ \\
\hline & Handlebar-V (cm) & $9.7 \pm 1.8$ & $9.2 \pm 2.1$ & $7.8 \pm 2.5$ & $8.9 \pm 2.2$ \\
\hline
\end{tabular}

BMI, body mass index. \%IL, percentage of inseam length. Handlebar-D, distance between

the front of the saddle and the middle of the handlebars. Handlebar- $\mathrm{V}$, vertical distance between the top of the saddle and the handlebar's brake. Significant differences $(p<0.05)$ : * Professionals $v s$ Elite, $\uparrow$ Professionals vs Club, $\uparrow$ Elite $v s$ Club. 
Table 2. Kinetic analysis (Mean \pm SD) of the three groups of cyclists (Professionals, Elite and Club) at different pedalling power outputs (200, 250 and $300 \mathrm{~W})$.

\begin{tabular}{|c|c|c|c|c|c|}
\hline & & $\begin{array}{c}\text { Professionals } \\
(\mathrm{n}=11)\end{array}$ & $\begin{array}{c}\text { Elite } \\
(n=13)\end{array}$ & $\begin{array}{c}\text { Club } \\
(n=14)\end{array}$ & $\begin{array}{l}\text { All cyclists } \\
(\mathrm{n}=38)\end{array}$ \\
\hline \multirow{3}{*}{ 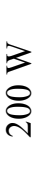 } & Maximum torque $(\mathrm{N} \cdot \mathrm{m})$ & $44.5 \pm 3.2$ & $47.6 \pm 3.6 *$ & $47.2 \pm 3.4 *$ & $46.7 \pm 3.7$ \\
\hline & Minimum torque $(\mathrm{N} \cdot \mathrm{m})$ & $-10.4 \pm 2.2$ & $-12.3 \pm 2.5$ & $-13.2 \pm 3.0 *$ & $-12.1 \pm 2.8$ \\
\hline & PIP (\%) & $82.0 \pm 2.4$ & $80.5 \pm 2.6$ & $80.0 \pm 2.8$ & $80.7 \pm 2.7$ \\
\hline \multirow{3}{*}{\begin{tabular}{l}
3 \\
0 \\
\multirow{2}{*}{}
\end{tabular}} & Maximum torque $(\mathrm{N} \cdot \mathrm{m})$ & $51.2 \pm 4.1$ & $54.0 \pm 4.6$ & $54.5 \pm 3.0 *$ & $53.4 \pm 4.1 \#$ \\
\hline & Minimum torque $(\mathrm{N} \cdot \mathrm{m})$ & $-9.0 \pm 2.1$ & $-11.3 \pm 2.5 *$ & $-12.0 \pm 2.5 *$ & $-10.9 \pm 2.6 \#$ \\
\hline & PIP (\%) & $86.5 \pm 2.3$ & $84.3 \pm 2.5 *$ & $84.1 \pm 2.6 *$ & $84.9 \pm 2.6 \#$ \\
\hline \multirow{3}{*}{$\begin{array}{l}3 \\
\stackrel{8}{8}\end{array}$} & Maximum torque $(\mathrm{N} \cdot \mathrm{m})$ & $57.2 \pm 4.4$ & $58.7 \pm 4.5$ & $60.0 \pm 2.9$ & $58.7 \pm 4.0 \# \&$ \\
\hline & Minimum torque $(\mathrm{N} \cdot \mathrm{m})$ & $-7.7 \pm 2.1$ & $-9.5 \pm 2.7 \dagger *$ & $-11.0 \pm 1.9 *$ & $-9.5 \pm 2.6 \# \&$ \\
\hline & PIP (\%) & $90.9 \pm 2.8$ & $88.2 \pm 2.9 *$ & $87.4 \pm 2.1 *$ & $88.7 \pm 3.0 \# \&$ \\
\hline \multirow{3}{*}{ 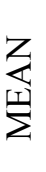 } & Maximum torque $(\mathrm{N} \cdot \mathrm{m})$ & $51.0 \pm 6.5$ & $53.3 \pm 6.2$ & $53.9 \pm 6.0 *$ & $58.7 \pm 4.0$ \\
\hline & Minimum torque $(\mathrm{N} \cdot \mathrm{m})$ & $-9.1 \pm 2.4$ & $-11.0 \pm 2.8 \dagger *$ & $-12.1 \pm 2.6 *$ & $-9.5 \pm 2.6$ \\
\hline & PIP (\%) & $86.5 \pm 4.5$ & $84.3 \pm 4.1 *$ & $83.7 \pm 3.9 *$ & $88.7 \pm 3.0$ \\
\hline
\end{tabular}

PIP, positive impulse proportion. Significant differences $(\mathrm{p}<0.05)$ : with professional cyclists

$(*)$, Elite vs Club cyclists $(\dagger)$. Significant differences $(\mathrm{p}<0.001)$ with $200(\#)$ and $250 \mathrm{~W}(\&)$. 
Table 3. Kinematic analysis (hip, knee and ankle joints) of the three groups of cyclists (Professionals, Elite and Club). Mean \pm SD values of the three power outputs (200, 250 and $300 \mathrm{~W})$.

\begin{tabular}{|c|c|c|c|c|c|}
\hline & & $\begin{array}{c}\text { Professionals } \\
(\mathrm{n}=11)\end{array}$ & $\begin{array}{c}\text { Elite } \\
(\mathrm{n}=13)\end{array}$ & $\begin{array}{c}\text { Club } \\
(\mathrm{n}=14)\end{array}$ & $\begin{array}{l}\text { All cyclists } \\
\quad(\mathrm{n}=38)\end{array}$ \\
\hline \multirow{3}{*}{ 主 } & Extension $\left({ }^{\circ}\right)$ & $64.9 \pm 1.5$ & $62.3 \pm 2.6$ & $63.6 \pm 2.5$ & $63.4 \pm 2.6$ \\
\hline & Flexion $\left({ }^{\circ}\right)$ & $21.6 \pm 1.9$ & $18.8 \pm 2.4 *$ & $19.4 \pm 2.9 *$ & $19.9 \pm 2.8$ \\
\hline & $\mathrm{ROM}\left({ }^{\circ}\right)$ & $43.2 \pm 1.4$ & $43.5 \pm 2.1$ & $44.3 \pm 3.4$ & $43.6 \pm 2.6$ \\
\hline \multirow{3}{*}{$\underset{\underline{Z}}{\underline{\underline{I}}}$} & Extension $\left({ }^{\circ}\right)$ & $146.4 \pm 3.1$ & $146.0 \pm 4.0$ & $144.5 \pm 2.9$ & $145.4 \pm 3.8$ \\
\hline & Flexion $\left({ }^{\circ}\right)$ & $70.5 \pm 2.9$ & $70.7 \pm 2.0$ & $69.6 \pm 3.0$ & $70.2 \pm 2.7$ \\
\hline & $\operatorname{ROM}\left({ }^{\circ}\right)$ & $75.8 \pm 1.9$ & $75.2 \pm 3.6$ & $75.0 \pm 4.4$ & $75.2 \pm 3.5$ \\
\hline \multirow{3}{*}{$\frac{\sqrt{3}}{\frac{\nabla}{Z}}$} & Extension $\left({ }^{\circ}\right)$ & $136.5 \pm 4.7$ & $136.5 \pm 6.4$ & $134.2 \pm 6.3$ & $135.8 \pm 6.0$ \\
\hline & Flexion $\left({ }^{\circ}\right)$ & $112.9 \pm 6.6$ & $114.0 \pm 6.5$ & $114.6 \pm 7.4$ & $113.8 \pm 7.0$ \\
\hline & ROM & $23.6 \pm 4.6$ & $22.5 \pm 6.1 \dagger$ & $19.6 \pm 6.0$ * & $21.9 \pm 6.0$ \\
\hline
\end{tabular}

ROM, range of movement. Significant differences $(\mathrm{p}<0.05)$ : Significant differences

$(\mathrm{p}<0.05)$ : with professional cyclists $(*)$, Elite $v s$ Club cyclists $(\dagger)$. 
Table 4. Mean $\pm \mathrm{SD}$ of the kinetic analysis (at 200, 250 and $300 \mathrm{~W}$ ) and kinematic analysis (hip, knee and ankle) during pedalling at 200, 250 and $300 \mathrm{~W}$ before and after the preseason in professional cyclists.

\begin{tabular}{|c|c|c|c|}
\hline & & $\begin{array}{c}\text { Before } \\
(n=9)\end{array}$ & $\begin{array}{l}\text { After } \\
(n=9)\end{array}$ \\
\hline \multicolumn{4}{|c|}{ Kinetic analysis } \\
\hline \multirow{3}{*}{$\begin{array}{l}3 \\
\stackrel{8}{8}\end{array}$} & Maximum torque $(\mathrm{N} \cdot \mathrm{m})$ & $44.9 \pm 3.5$ & $44.1 \pm 3.6$ \\
\hline & Minimum torque $(\mathrm{N} \cdot \mathrm{m})$ & $-11.3 \pm 3.2 *$ & $-10.3 \pm 2.2$ \\
\hline & PIP $(\%)$ & $81.7 \pm 3.6$ & $82.0 \pm 2.5$ \\
\hline \multirow{3}{*}{$\begin{array}{l}3 \\
0 \\
i\end{array}$} & Maximum torque $(\mathrm{N} \cdot \mathrm{m})$ & $50.8 \pm 4.4$ & $50.9 \pm 3.2$ \\
\hline & Minimum torque $(\mathrm{N} \cdot \mathrm{m})$ & $-9.7 \pm 3.2$ & $-9.0 \pm 2.2$ \\
\hline & PIP $(\%)$ & $86.5 \pm 3.5$ & $86.5 \pm 2.4$ \\
\hline \multirow{3}{*}{$\begin{array}{l}3 \\
8\end{array}$} & Maximum torque $(\mathrm{N} \cdot \mathrm{m})$ & $58.6 \pm 4.6$ & $58.0 \pm 4.7$ \\
\hline & Minimum torque $(\mathrm{N} \cdot \mathrm{m})$ & $-9.0 \pm 3.1 *$ & $-7.9 \pm 2.7$ \\
\hline & PIP $(\%)$ & $88.1 \pm 3.0 *$ & $89.5 \pm 2.6$ \\
\hline \multirow{3}{*}{ 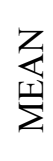 } & Maximum torque $(\mathrm{N} \cdot \mathrm{m})$ & $50.5 \pm 6.7$ & $50.6 \pm 6.3$ \\
\hline & Minimum torque $(\mathrm{N} \cdot \mathrm{m})$ & $-10.1 \pm 3.6^{*}$ & $-9.0 \pm 2.4$ \\
\hline & PIP $(\%)$ & $85.7 \pm 4.7$ & $86.4 \pm 4.5$ \\
\hline \multicolumn{4}{|c|}{ Kinematic analysis } \\
\hline \multirow{3}{*}{ 主 } & Extension $\left(^{\circ}\right)$ & $64.9 \pm 1.6$ & $65.1 \pm 1.7$ \\
\hline & Flexion $\left({ }^{\circ}\right)$ & $21.8 \pm 2.0$ & $21.8 \pm 1.9$ \\
\hline & $\mathrm{ROM}\left({ }^{\circ}\right)$ & $43.2 \pm 1.5$ & $43.3 \pm 1.3$ \\
\hline \multirow{3}{*}{ 崩 } & Extension $\left({ }^{\circ}\right)$ & $146.4 \pm 3.1$ & $146.9 \pm 3.6$ \\
\hline & Flexion $\left({ }^{\circ}\right)$ & $70.5 \pm 2.9$ & $70.5 \pm 2.8$ \\
\hline & $\mathrm{ROM}\left({ }^{\circ}\right)$ & $75.9 \pm 2.0$ & $76.4 \pm 2.4$ \\
\hline \multirow{3}{*}{ 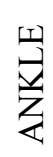 } & Extension $\left({ }^{\circ}\right)$ & $136.0 \pm 4.3$ & $136.2 \pm 4.5$ \\
\hline & Flexion $\left(^{\circ}\right)$ & $112.6 \pm 6.6$ & $111.5 \pm 6.6$ \\
\hline & $\operatorname{ROM}\left({ }^{\circ}\right)$ & $23.4 \pm 4.5$ & $24.7 \pm 4.2$ \\
\hline
\end{tabular}

PIP, positive impulse proportion. ROM, range of movement. * Significant difference $(\mathrm{p}<0.05)$. 


\section{Figure captions}

Figure 1. The main bike measurements: saddle height, saddle back, crank arm length, vertical distance between the top of the saddle and the handlebar's brake (Handlebar-V) and distance between the front of the saddle and the middle of the handlebars (Handlebar-D).

Figure 2. Biomechanical variables analysed during pedalling. Kinetic analysis: torque-angle profile of a complete revolution and main selected variables for analysis. Kinematic analysis: schematic illustration of reflective marker locations and definition of angles. 
The main bike measurements: saddle height, saddle back, crank arm length, vertical distance between the top of the saddle and the handlebar's brake (Handlebar-V) and distance between the front of the saddle and the middle of the handlebars (Handlebar-D). $211 \times 135 \mathrm{~mm}(150 \times 150 \mathrm{DPI})$ 

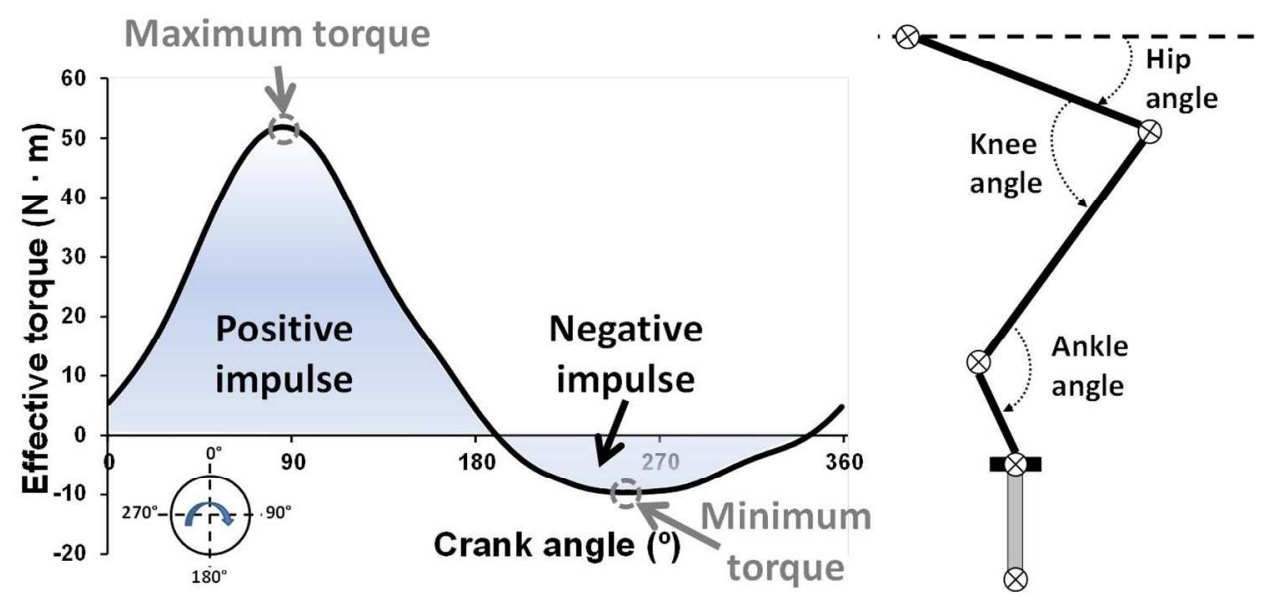

Biomechanical variables analysed during pedalling. Kinetic analysis: torque-angle profile of a complete revolution and main selected variables for analysis. Kinematic analysis: schematic illustration of reflective marker locations and definition of angles. $250 \times 134 \mathrm{~mm}(150 \times 150 \mathrm{DPI})$ 